\title{
DDX10/NUP98 Fusion Gene
}

National Cancer Institute

\section{Source}

National Cancer Institute. DDX10/NUP98 Fusion Gene. NCI Thesaurus. Code C99445.

A fusion gene that results from a chromosomal inversion inv(11)(p15q22) which fuses the first half of the NUP98 gene to the 3' portion of the DDX10 gene. This fusion is associated with both with de novo and therapy-related acute myeloid leukemia and myelodysplastic syndrome. 